\title{
COMPARING STUDENT PERFORMANCE: ONLINE VERSUS BLENDED VERSUS FACE-TO-FACE
}

\author{
David K. Larson \\ University of Illinois at Springfield \\ Department of Management Information Systems \\ College of Business and Management
}

\author{
Chung-Hsien Sung \\ Department of Mathematical Sciences \\ College of Liberal Arts and Sciences
}

\begin{abstract}
The purpose of this research was to perform a three way comparison of delivery modes for an introductory Management Information Systems course to determine if there existed a difference in student success among the delivery modes. The research compares student exam and final grade results in this class that was taught by the same instructor using face-to-face, blended and online delivery modes. An Analysis of Variance test was used on the exam and final grade data to determine if a significant difference existed. Additionally, a discussion of this class in relation to student satisfaction, learning effectiveness and faculty satisfaction is presented. This research demonstrates that there is no significant difference among delivery modes. Additionally, blended and online modes for this class do very well when measuring student satisfaction, learning effectiveness and faculty satisfaction.
\end{abstract}

\section{KEYWORDS}

Online, Blended, Face-to-Face, No Significant Difference, Leaning Mode Comparison

\section{INTRODUCTION}

The purpose of this research was to determine if there is a significant difference in student success in an introductory Management Information Systems class delivered in three different modes; face-to-face, blended, and online. This paper presents a three way comparison of student success using these modes of delivery. This research differs from other research in this area in that it compares all three modes, rather than the two way comparisons typically found in the literature. A search of the literature has not, to this point, discovered research that does a three way comparison of these delivery modes.

Based on the research performed over the last several years, it has become a foregone conclusion that there is no significant difference in student learning outcomes between face-to-face versus online delivery modes [1, 2, 3]. Additionally, the website http://www.nosignificantdifference.org contains hundreds of articles showing that there is no significant difference between face-to-face and online delivery modes. Another delivery method, blended, is emerging as a new mode of delivery and must past this same test. In the past, face-to-face delivery methods were considered the standard against which other delivery methods were measured. Now, given the research on online delivery, we can use both or either face-to- 
face or online delivery methods as the measure of other techniques such as blended.

Blended learning combines multiple modes of delivery for delivering course content to students. Typically, and in the context of this study, the multiple modes are face-to-face and online [4, 5, 6, 7, 8]. The idea is to use the best or most appropriate features of each method to help enhance the student experience and maximize the possibility of student success.

Studies comparing different types of media are not new. As Clark [10] points out, "Studies of the influence of media on learning have been a fixed feature of educational research since Thorndike (1912) recommended pictures as a labor saving device in instruction." Additionally, since the introduction of the computer, numerous studies have been conducted trying to determine if computer technology improves learning. Kulik $[11,12,13]$ and his colleagues conclude in their meta-analysis of numerous studies that "computer-based instruction (CBI) usually produces positive effects on students." Additionally, Yuenkuang's [19] study concludes that Computer Assisted Instruction (CAI) is more effective than traditional instruction in Taiwan. Clark [10] on the other hand finds that, "Consistent evidence is found for the generalization that there are no learning benefits to be gained from employing any specific medium to deliver instruction.” Kozma [14] argues that success is found when the "capabilities of the medium" are employed. And, Jenks and Springer [15] conclude that "CAI should be at least as effective as conventional instruction.”

If we take Marshall McLuhan's famous quote "the medium is the message" and view it from a somewhat surface level, we might think that he would support those who conclude that computer technology (medium) does provide benefits. And, that he indeed would support all this analysis of "medium" such as computers and the Internet. McLuhan recognized the impact of what he called "electric technology" was going to have on society; "The medium, or process, of our time-electric technology—is reshaping and restructuring patterns of social interdependence and every aspect of our personal life. It is forcing us to reconsider and reevaluate practically every thought, every action, and every institution formerly taken for granted. Everything is changing-you, your family, your neighborhood, your education, your job, your government, your relation to 'the other.' And they're changing dramatically” [16]. Studies such as this one and others, are certainly reconsidering and reevaluating the impact of these technologies on learning. We will discuss MuLuhan more later on in the paper.

It is entirely appropriate that we try to figure out how we can improve learning using new technologies. As Kenny [17] points out; "A change in educational techniques is inevitable. What must be done is to figure out how and when, not if, this new combine [digital convergence] will be incorporated into the instructional designers' thinking about the current batch of students, who are steeped in exposure to new media."

\section{STUDY BACKGROUND}

This study focuses on an introductory Management Information Systems course. The course is a required core course for any student pursuing a bachelor's degree from the University of Illinois at Springfield's College of Business and Management. It should be noted that there is currently no Management Information Systems bachelor's degree offered at this university. Consequently, none of the students taking this class are majoring in Management Information Systems. The course has been taught, by the same instructor, in three delivery modes; face-to-face, online, and blended. The university is on a semester format with sixteen class meetings during the semester. All class sections used the same textbook and supporting materials. 
The face-to-face sections followed a typical face-to-face format with the textbook and lectures being the primary mode of providing content to students. Students did have lecture notes available through a course management system. Students needed an access key from the book publisher to access the lecture notes area and acquisition of this key was not required. Face-to-face sections met all sixteen sessions with three of the sessions being used for exams.

The online section was conducted in a typical online format. For the online section the textbook and lecture notes, delivered through a course management system, were the primary modes of providing content to students. Students in the online class were required to acquire the access key from the publisher for access to the lecture notes. In the online section, students were required to participate in weekly asynchronous online discussions. Several discussion questions were posted on the class course management system site and students were required to provide a comprehensive answer to one of the discussion questions posted. Students were also required to respond to another student's answer. Exams were taken at proctor locations selected by the students. Proctor locations were required to be a university or college, library, or military installation. Additionally, the proctor was required to check photo identification before providing the test to the student.

The blended sections were a combination of the face-to-face format and online format. The class met in the face-to-face format for eleven sessions and the online format for five sessions. Three of the eleven face-to-face sessions were used for exams. During the online sessions, students were required to participate in online asynchronous discussions with the same expectations as for the online sections. Students did have lecture notes available through a course management system. Students needed an access key from the book publisher to access the lecture notes area and acquisition of this key was not required.

With the exception of the graded online discussions that occurred in the online and blended sections, all homework assignments were the same with the same expectations. While the face-to-face sections did not have graded discussions, the discussion question topics were discussed in class. Assignment expectations were provided through assignment rubrics.

In all cases above three exams were given. The exams consisted of true/false, multiple choice and essay questions. For all sections the true/false and multiple choice question portions of the tests were identical. The essay questions were not identical but were similar. The analysis below looks at the exam results with and without essay scores.

\section{PROCEDURES}

Study participants included 168 students who took an introductory Principles of Management Information Systems course. The course is a required core course for any student pursuing a bachelor's degree from the university's College of Business and Management. Of the 168 students, 63 participated in the face-toface sections, 22 participated in the online section, and 83 participated in the blended sections. An analysis of the students enrolled (data was acquired from the university's enrollment data) in the class sections studied, indicates there is no significant difference in students based on race (Table 1) and age (Table 2). However the analysis did find a significant difference based on gender. While the male and female ratios are similar in the face-to-face and blended sections, the online section has significantly more females (Table 3). While this does show dissimilarity among the modes of delivery, it is not an uncommon difference. Several sources reviewed indicate that females tend to be the majority in online classes [20, 21, 22]. Consequently, it can be assumed that many analyses comparing the online delivery 
mode to other delivery modes will have this characteristic.

\begin{tabular}{|c|c|c|c|c|}
\hline Observed & White & \multicolumn{2}{|l|}{ Non-White } & $\mathrm{P}$-value \\
\hline F2F & 51 & 9 & 60 & \\
\hline Blended & 78 & 13 & 91 & \\
\hline \multirow[t]{2}{*}{ On-Line } & 22 & 1 & 23 & \\
\hline & 151 & 23 & 174 & \\
\hline Expected & White & \multicolumn{2}{|l|}{ Non-White } & \\
\hline F2F & 52.06897 & 7.931034 & 60 & \\
\hline Blended & 78.97126 & 12.02874 & 91 & \\
\hline \multirow[t]{2}{*}{ On-Line } & 19.95977 & 3.04023 & 23 & \\
\hline & 151 & 23 & 174 & \\
\hline \multicolumn{5}{|l|}{ Chi-Sq } \\
\hline & 0.021946 & 0.144078 & & \\
\hline & 0.011946 & 0.078425 & & \\
\hline & 0.208546 & 1.369152 & & \\
\hline & & & 1.834093 & 0.399698 \\
\hline
\end{tabular}

Table 1. Analysis of Race

\begin{tabular}{|l|r|r|c|r|r|}
\hline Source & \multicolumn{1}{|c|}{ d.f. } & \multicolumn{1}{c|}{ S.S. } & M.S. & F* & P-value \\
\hline Group & 2 & 216.28416 & 108.1421 & 1.5 & 0.2251 \\
\cline { 1 - 4 } Error & 171 & 12291.3538 & 71.87926 & & \\
\cline { 1 - 4 } $\begin{array}{l}\text { Corrected } \\
\text { Total }\end{array}$ & 173 & 12507.6379 & & & \\
\hline
\end{tabular}

Table 2. Analysis of Age

\begin{tabular}{|l|r|r|r|l|l|}
\hline Observed & \multicolumn{1}{l|}{ Male } & Female & & & P-value \\
\hline F2F & 28 & 32 & 60 & & \\
\hline Blended & 54 & 37 & 91 & & \\
\hline On-Line & 6 & 17 & 23 & & \\
\hline & 88 & 86 & 174 & & \\
\hline & & & & & \\
\hline Expected & Male & Female & & & \\
\hline F2F & 30.34483 & 29.65517 & 60 & & \\
\hline Blended & 46.02299 & 44.97701 & 91 & & \\
\hline On-Line & 11.63218 & 11.36782 & 23 & & \\
\hline & 88 & 86 & 174 & & \\
\hline Chi-Sq & & & & & \\
\hline & 0.181191 & 0.185405 & & & \\
\hline & 1.382629 & 1.414783 & & & \\
\hline & 2.727046 & 2.790465 & & & \\
\hline & & & 8.681519 & & 0.013027 \\
\hline
\end{tabular}

Table 3. Analysis of Gender 
To determine if there was a difference in student success among the three modes of delivery for this class, student exam scores and final class grade were used. For purposes of this research, exam scores were analyzed in two ways. First, exam scores were analyzed with the essay portions of the exams excluded from the analysis. The reason for excluding the essay questions for the analysis is due to these questions not being identical for all exams. Only the true/false and multiple choice questions in all exams were identical. Second, exam scores which include the essay questions were analyzed. Third, student's final grade in the class was analyzed.

Lastly, student evaluations were analyzed in relation to student satisfaction, learning effectiveness and faculty satisfaction. For the sets of data for exams and the final grade, an Analysis of Variance test was used.

\section{RESULTS}

\section{A. Exam Score Analysis}

First, using average exam scores without essay questions (Table 4), which are expressed in the number of questions the student missed hence the negative numbers, the Analysis of Variance test was run using a .05 level of significance. The test was based on the following null hypothesis:

$\mathrm{H}_{0} \quad$ = average exam score without essay questions for Face-to-face Group

= average exam score without essay questions for Blended Group

= average exam score without essay questions for Online Group

\begin{tabular}{|l|l|l|l|}
\hline \multicolumn{1}{|c|}{ Group } & \multicolumn{1}{c|}{$\begin{array}{c}\text { Exam 1 } \\
\text { Total Points }=83\end{array}$} & $\begin{array}{c}\text { Exam 2 } \\
\text { Total Points }=84\end{array}$ & $\begin{array}{c}\text { Exam 3 } \\
\text { Total Points }=78\end{array}$ \\
\hline Face-to-face & $-17.56 \pm 1.26$ & $-19.11 \pm 1.31$ & $-19.77 \pm 1.13$ \\
\hline Blended & $-18.39 \pm 1.02$ & $-21.13 \pm 1.22$ & $-21.57 \pm 1.19$ \\
\hline Online & $-18.18 \pm 2.07$ & $-24.77 \pm 2.05$ & $-23.73 \pm 2.03$ \\
\hline
\end{tabular}

Table 4. Summary (Mean \pm Standard Error) — Exams Without Essay Questions

Next, using average exam scores with essay questions included (Table 5), which are expressed in the percentages, the Analysis of Variance test was run using a .05 level of significance. The test was based on the following null hypothesis:

$\mathrm{H}_{0} \quad$ = average exam score with essay questions for Face-to-face Group

= average exam score with essay questions for Blended Group

= average exam score with essay questions for Online Group

\begin{tabular}{|l|r|r|r|}
\hline \multicolumn{1}{|c|}{ Group } & Exam 1 & Exam 2 & Exam 3 \\
\hline Face-to-face & $84.11 \pm 1.19$ & $79.74 \pm 1.52$ & $80.15 \pm 1.18$ \\
\hline Blended & $82.22 \pm 0.96$ & $76.54 \pm 1.28$ & $79.33 \pm 1.23$ \\
\hline Online & $84.25 \pm 1.81$ & $74.43 \pm 2.37$ & $79.05 \pm 2.24$ \\
\hline
\end{tabular}

Table 5. Summary (Mean \pm Standard Error) - Exams With Essay Questions

Since all P-values are $>0.05$ (Tables 6 thru 11), the level of significance used in the test, the results of the 
Analysis of Variance tests indicate there is no significant difference among the average exam scores with or without essay questions among face-to-face, online and blended sections of the course.

\begin{tabular}{|l|r|r|r|r|r|}
\hline Source & \multicolumn{1}{|c|}{ d.f. } & \multicolumn{1}{c|}{ S.S. } & \multicolumn{1}{|c|}{ M.S. } & \multicolumn{1}{|c|}{ F* $^{*}$} & P-value \\
\cline { 1 - 4 } Group & 2 & 25.12811 & 12.56406 & 0.14 & 0.8729 \\
\cline { 1 - 4 } Error & 165 & 15242.49093 & 92.37873 & & \\
\cline { 1 - 4 } Total & 167 & 15267.61905 & & & \\
\hline
\end{tabular}

Table 6. Analysis of Variance - Exam 1 Without Essay Questions

\begin{tabular}{|l|r|r|r|r|r|}
\hline Source & \multicolumn{1}{|c|}{ d.f. } & \multicolumn{1}{c|}{ S.S. } & \multicolumn{1}{c|}{ M.S. } & \multicolumn{1}{c|}{ F* $^{*}$} & P-value \\
\hline Group & 2 & 528.21781 & 264.10891 & \multirow{2}{*}{2.41} & 0.0935 \\
\cline { 1 - 4 } Error & 159 & 17456.79453 & 109.79116 & & \\
\cline { 1 - 4 } Total & 161 & 17985.01235 & & & \\
\hline
\end{tabular}

Table 7. Analysis of Variance - Exam 2 Without Essay Questions

\begin{tabular}{|l|r|r|r|r|r|}
\hline Source & \multicolumn{1}{|c|}{ d.f. } & \multicolumn{1}{c|}{ S.S. } & \multicolumn{1}{c|}{ M.S. } & \multicolumn{1}{c|}{$\mathrm{F}^{*}$} & P-value \\
\cline { 1 - 4 } Group & 2 & 276.57035 & 138.28518 & \multirow{2}{*}{1.47} & 0.2338 \\
\cline { 1 - 4 } Error & 157 & 14799.87340 & 94.26671 & & \\
\hline Total & 159 & 15076.44375 & & & \\
\hline
\end{tabular}

Table 8. Analysis of Variance - Exam 3 Without Essay Questions

\begin{tabular}{|r|r|r|r|r|r|}
\hline Source & d.f. & S.S. & M.S. & $\mathrm{F}^{*}$ & P-value \\
\cline { 1 - 4 } Group & 2 & 156.04934 & 78.02467 & 0.97 & 0.3831 \\
\cline { 1 - 4 } Error & 165 & 13338.49948 & 80.83939 & & \\
\cline { 1 - 4 } Total & 167 & 13494.54881 & & & \\
\hline
\end{tabular}

Table 9. Analysis of Variance - Exam 1 With Essay Questions

\begin{tabular}{|r|r|r|r|r|r|}
\hline Source & d.f. & S.S. & M.S. & $\mathrm{F}^{*}$ & P-value \\
\cline { 1 - 4 } Group & 2 & 587.12146 & 293.56073 & 2.21 & 0.1132 \\
\cline { 1 - 4 } Error & 159 & 21129.47153 & 132.88976 & & \\
\hline Total & 161 & 21716.59299 & & & \\
\hline
\end{tabular}

Table 10. Analysis of Variance - Exam 2 With Essay Questions

\begin{tabular}{|r|r|r|r|r|r|}
\hline Source & d.f. & S.S. & M.S. & $\mathrm{F}^{*}$ & P-value \\
\cline { 1 - 4 } Group & 2 & 30.76684 & 15.38342 & 0.15 & 0.8622 \\
\cline { 1 - 4 } Error & 157 & 16268.11034 & 103.61854 & & \\
\cline { 1 - 4 } Total & 159 & 16298.87718 & & & \\
\hline
\end{tabular}

Table 11. Analysis of Variance - Exam 3 With Essay Questions

\section{B. Final Class Grade Analysis}

Prior to performing the analysis for the final class grade, seven students were removed from the data. 
These seven students dropped the class without officially dropping through the university's registration system. While they were still enrolled in the class each student missed at least the last exam and stopped doing assignments and participating in the class.

Using the average final class grades (Table 12), which are expressed in the percentages, the Analysis of Variance test was run using a .05 level of significance. The test was based on the following null hypothesis:

$$
\begin{aligned}
\mathrm{H}_{0} & =\text { average final class grade for Face-to-face Group } \\
& =\text { average final class grade for Blended Group } \\
& =\text { average final class grade for Online Group }
\end{aligned}
$$

\begin{tabular}{|l|l|}
\hline \multicolumn{1}{|c|}{ Group } & \multicolumn{1}{c|}{$\begin{array}{c}\text { Final Class } \\
\text { Grade }\end{array}$} \\
\hline Face-to-face & $84.21 \pm 1.05$ \\
\hline Blended & $81.55 \pm 1.19$ \\
\hline Online & $84.20 \pm 1.91$ \\
\hline
\end{tabular}

Table 12. Summary (Mean \pm Standard Error) — Final Class Grade

Since the P-value is $>0.05$ (Table 13), the level of significance used in the test, the results of the Analysis of Variance tests indicate there is no significant difference among the average final class grades among face-to-face, online and blended sections of the course.

\begin{tabular}{|l|r|r|r|r|r|}
\hline Source & \multicolumn{1}{|c|}{ d.f. } & \multicolumn{1}{c|}{ S.S. } & \multicolumn{1}{c|}{ M.S. } & \multicolumn{1}{c|}{ F $^{*}$} & P-value \\
\hline Group & 2 & 281.38052 & 140.69026 & \multirow{2}{*}{1.59} & \multirow{2}{*}{0.2066} \\
\cline { 1 - 4 } Error & 157 & 13867.05675 & 88.32520 & & \\
\cline { 1 - 4 } Total & 159 & 14148.43728 & & & \\
\hline
\end{tabular}

Table 13. Analysis of Variance - Final Class Grade

\section{Student Evaluation Analysis}

In addition to the analysis of student results on exams and final class grades, student evaluations were also analyzed in relation to student satisfaction, learning effectiveness and faculty satisfaction. The university where this course is taught requires that students are given an opportunity to evaluate each class they take. The university provides a standard evaluation instrument that is required to be used. The evaluation is anonymous and students are not required to complete the evaluation. While the evaluation has ten questions, one question from the evaluation is relevant to student satisfaction, two questions are relevant to learning effectiveness and one question is relevant to faculty satisfaction. The student evaluation response rates are $95.45 \%$ for online, $70.73 \%$ for blended and $95.08 \%$ for face-to-face. The results for these four questions are found in the discussion which follows.

\section{DISCUSSION}

The discussion herein is based on the categories contained within Sloan-C's Effective Practices. "Sloan-C focuses on five pillars of quality in online education: student satisfaction, access, learning effectiveness, faculty satisfaction and institutional cost effectiveness” [9]. Within this article we will confine our discussion to the categories of student satisfaction, learning effectiveness and faculty satisfaction. While 
Sloan-C practices focus on online learning, the authors felt the categories were an appropriate means for organizing the remainder of our discussion.

\section{A. Student Satisfaction}

This question related to student satisfaction is discussed below.

Question: As a result of taking this course, my interest in this subject has: student response options are; Decreased, Stayed the Same, Increased and No Response.

It appears from the student responses (Table 14), that no matter what the delivery mode, nearly forty percent or more of the students had an increase in interest in this subject. Given that no students taking this course are majoring in Management Information Systems, this statistic is encouraging. Also seeing that no more than fifteen percent of the students had a decrease in interest in the subject is again encouraging. One could assume that if the delivery mode were affecting the student's interest, one of the modes would stand out but, in this case all ratings are fairly consistent.

\begin{tabular}{|l|c|c|c|c|}
\hline & Decreased & Stayed the Same & Increased & No Response \\
\hline Average for Online & $9.52 \%$ & $52.38 \%$ & $38.10 \%$ & $0 \%$ \\
\hline Average for Blended & $14.84 \%$ & $33.19 \%$ & $51.97 \%$ & $0 \%$ \\
\hline Average for Face-to-Face & $12.01 \%$ & $48.51 \%$ & $39.49 \%$ & $0 \%$ \\
\hline
\end{tabular}

Table 14. Interest In Subject Evaluation Results

Using the above question and the resulting student ratings, it does not appear that any of the delivery modes stands apart from the other in either positive or negative terms. Student interest was rated in the positive direction.

\section{B. Learning Effectiveness}

Learning effectiveness is measured by Sloan-C as the following: "The course or program is designed to be at least equivalent in quality to face-to-face courses offered at the same institution.” This course is built around specific learning outcomes that are the foundation for exams and final grades. The research done as part of this paper indicates that using exam scores and the final grade for the class, no significant difference exists among the three delivery modes used for this class. Consequently, the online and blended modes of delivery for this class are at least equivalent to the face-to-face mode. Additionally, two questions from the student evaluations address learning effectiveness. These questions are discussed below.

Question: This course has increased my critical thinking: student response options are; Yes, No, No Response.

Since face-to-face is traditionally the standard by which other modes of delivery are measured, seeing that both blended and online provide a higher rating for increased critical thinking (Table 15) is an indication that they are no worse and arguably better than face-to-face. 


\begin{tabular}{|l|c|c|c|}
\hline & Yes & No & No Response \\
\hline Average for Online & $80.95 \%$ & $14.29 \%$ & $0 \%$ \\
\hline Average for Blended & $75.69 \%$ & $24.31 \%$ & $0 \%$ \\
\hline Average for Face-to-Face & $62.61 \%$ & $37.40 \%$ & $0 \%$ \\
\hline
\end{tabular}

Table 15. Critical Thinking Evaluation Results

Question: This course has motivated me to work at my highest level: student response options are; Yes, No, No Response.

Again, using face-to-face as the standard, more online and blended students indicated they were motivated to work at their highest level in these sections than in the face-to-face sections (Table 16).

\begin{tabular}{|l|c|c|c|}
\hline & Yes & No & No Response \\
\hline Average for Online & $71.43 \%$ & $28.57 \%$ & $0 \%$ \\
\hline Average for Blended & $78.07 \%$ & $21.93 \%$ & $0 \%$ \\
\hline Average for Face-to-Face & $51.98 \%$ & $48.03 \%$ & $0 \%$ \\
\hline
\end{tabular}

Table 16. Work Motivation Evaluation Results

The one possible exception to this, being the critical thinking rating for the face-to-face class, it is the closest rating to the negative direction. Perhaps this is influenced by discussions in the face-to-face sections not being graded. Since students are not required to prepare a response to the questions, they do not put in as much effort thinking about answers to the discussion topics. However, since face-to-face is the benchmark, having online and blended ratings higher reinforces that these delivery modes are at least as good as face-to-face. It appears that students are, for the most part, learning effectively in this class regardless of the delivery mode.

\section{Faculty Satisfaction}

The university where this course is offered is highly supportive of the online and blended modes of teaching. This is evident through the state-of-the-art technology infrastructure, high level of faculty support, stipends for course development, and in tenure and promotion decisions. The university is also supportive of faculty who perform research in this area.

A measure of faculty satisfaction relates to student evaluations. At this university, student evaluations play an important role in performance reviews. One question on the evaluation particularly relates to this area.

Question: Do you think this teacher is competent in the content or material offered in this course: student response options are a five scale range with three range titles being; incompetent, satisfactory and exceptionally competent, no response. When this question is used for performance reviews, the highest two ranges are combined for rating purposes. 


\begin{tabular}{|l|c|c|c|c|c|c|c|}
\hline & Incompetent & & Satisfactory & & $\begin{array}{c}\text { Exceptionally } \\
\text { Competent }\end{array}$ & $\begin{array}{c}\text { No } \\
\text { Response }\end{array}$ & $\begin{array}{c}\text { Highest } \\
\text { Two } \\
\text { Combined }\end{array}$ \\
\hline $\begin{array}{l}\text { Average } \\
\text { for Online }\end{array}$ & $0 \%$ & $4.76 \%$ & $4.76 \%$ & $14.29 \%$ & $76.19 \%$ & $0 \%$ & $90.48 \%$ \\
\hline $\begin{array}{l}\text { Average } \\
\text { for } \\
\text { Blended }\end{array}$ & $3.27 \%$ & $2.51 \%$ & $14.96 \%$ & $35.62 \%$ & $43.64 \%$ & $0 \%$ & $79.26 \%$ \\
\hline $\begin{array}{l}\text { Average } \\
\text { for Face- } \\
\text { to-Face }\end{array}$ & $0 \%$ & $1.85 \%$ & $23.12 \%$ & $38.11 \%$ & $36.92 \%$ & $0 \%$ & $75.03 \%$ \\
\hline
\end{tabular}

Table 17. Teacher Competency Evaluation Results

For performance rating purposes, the higher the percentage for the highest two categories, the better it is for the teacher. Given the ratings (Table 17), both online and blended resulted in a higher rating than faceto-face. This will consequently provide a more favorable rating for the teacher than the rating for face-toface.

The primary author for this article is the instructor for the course sections being analyzed in this study. While student evaluations are important, there are other factors that this instructor feels are related to his satisfaction. First, the instructor feels that the discussions in the online and blended sections are much richer than in the fact-to-face sections. In the online and blended sections, students tend to put more effort into their responses to the questions and all students participate. Were as in the face-to-face sections, students who respond, do not put as much thinking effort into their response. Additionally, a limited number of students tend to participate. Second, online particularly and blended somewhat provide the instructor with more freedom of time and place. The instructor has the freedom to work with the class when and where he finds most convenient. Third, the instructor feels there is more interaction with students in online and blended sections. While the interaction most often is not face-to-face, it occurs more frequently via private discussion areas and email. Consequently, it is the author's preference to teach using the online and blended delivery methods.

\section{CONCLUSIONS}

It appears from this research it can be concluded there is no significant difference in student performance, for this class, whether it is taught using the face-to-face, online or blended mode of delivery. While we cannot necessarily generalize these findings to all situations, this research does add to a body of research that supports there are no significant difference between face-to-face and online delivery modes. Additionally, the results show that there is no significant difference in student performance when comparing the blended mode of delivery to either face-to-face or online delivery modes.

Additionally, based upon student satisfaction, learning effectiveness and faculty satisfaction, both the blended and online versions of the class compare favorably to the face-to-face versions.

Let's revisit McLuhan. What does McLuhan mean by "the medium is the message"? According to Federman [18] the meaning is; "We can know the nature and characteristics of anything we conceive or create (medium) by virtue of the changes - often unnoticed and non-obvious changes - that they effect (message)." How does this relate to this study? It relates in that we have conceived or created media for helping students learn - traditionally face-to-face delivery and more recently online and blended delivery. 
We are still trying to figure out if these last two media are beneficial. Perhaps though we ought to be looking at one potential message these media are telling us. That message being, we have new ways of helping students learn that are just as good as the old way. Perhaps we should not focus so much on the technology aspect as on the assistance to learning aspect.

We may also be getting another message-people adapt. Since many of the studies result in a no significant difference conclusion maybe the message is it doesn't matter because people will adapt to the medium and learn. We have long argued about the delivery mechanisms and which were best to use. But, is this the real argument? Is this the right thing to focus on? It appears the body of literature is showing the medium may not matter.

Perhaps another message is the traditional mode of education delivery is prevalent only because there were no alternatives and now that there are alternatives, we have options and do not have to hold on to something that existed because it was our only option. It exists not because it has to, but it exists because it was the only option.

We can surmise from this that delivery mode may not be a major factor in student performance. Since there is no significant difference, it can be concluded that other factors may be more important such as course design, selection of the right content materials, instructor/student interaction, and/or student motivation may play a more important role than delivery mode. It seems that if the instructor uses best practices for whatever delivery mode they will be using, then the mode of delivery will not be a major factor in student performance.

\section{REFERENCES}

1. Newlin, M. H., J. L. Lavooy \& A. Y. Wang. An Experimental Comparison of Conventional and Web-based Instructional Formats. North American Journal of Psychology 7(2): 327-335, 2005.

2. Fallah, M. H. \& R. Ubell. Blind Scores in a Graduate Test: Conventional Compared with Web-based Outcomes. ALN Magazine 4(2): December 2000.

3. Mascuilli, A. B. Effectiveness of Teaching Mathematics Online. ALN Magazine 4(2): December 2000.

4. Reece, M. \& B. Lockee. Improving Training Outcomes Through Blended Learning. Journal of Asynchronous Learning Networks 9(4): 49-57, December 2005.

5. Picciano, A. G. Blended Learning: Implications for Growth and Access. Journal of Asynchronous Learning Networks 10(3): 95-102, July 2006.

6. Prendergast, G. Blended Collaborative Learning: Online Teaching of Online Educators. GlobalEducator: April 2004.

7. Osguthorpe, R. T. \& C. R. Graham. Blended Learning Environments Definitions and Directions. The Quarterly Review of Distance Education 4(3): 227-233, 2003.

8. Aspden, L. \& P. Helm. Making the Connection in a Blended Learning Environment. Educational Media International 41(3): 245-252, January 2004.

9. Sloan-C. Effective Practices, August 2005. Available online: http://www.sloan-c.org/effective index.asp.

10. Clark, R. Reconsidering Research on Learning from Media. Review of Educational Research 53(4): 445-459, Winter, 1983.

11. Kulik, J. A., C. C. Kulik \& P. A. Cohen. Effectiveness of Computer-Based College Teaching: A Meta-Analysis of Findings. Review of Educational Research 50(4): 525-544, Winter 1980.

12. Kulik, J. A., C. C. Kulik \& R. L. Bangert-Drowns. Effectiveness of Computer-Based Education in Elementary Schools. Computers in Human Behavior 1: 59-74, 1985. 
13. Kulik, C. C. \& J. A. Kulik. Effectiveness of Computer-Based Instruction: An Updated Analysis. Computers in Human Behavior 7: 75-94, 1991.

14. Kozma, R. B. Will Media Influence Learning? Reframing the Debate. Educational Technology Research and Development 42(2): 7-19, 1994.

15. Jenks, M. S. \& J. M. Springer. A View of the Research on the Efficacy of CAI. Electronic Journal for the Integration of Technology in Education 1(2): 2002. http://ejite.isu.edu/Volume1No2 /Jenks.htm.

16. McLuhan, M. The Medium is the Massage, First Edition, 8. New York: Bantam Books, 1967.

17. Kenny, R. Teaching, Learning, and Communicating in the Digital Age. Eric \# ED470091: 2001.

18. Federman, M. What is the Meaning of The Medium is the Message? July 23, 2004. http://individual.utoronto.ca/markfederman/article_mediumisthemessage.htm.

19. Yuen-kuang, C. L. Effects of Computer-Assisted Instruction on Students' Achievement in Taiwan: A Meta-Analysis. Computers \& Education 48(2): 216-233, February 2007.

20. Cavanaugh, J. K. Are Online Courses Cannibalizing Students From Existing Courses? Journal of Asynchronous Learning 9(3): 95-102, October 2005.

21. Illinois Virtual Campus. Sharpen the Focus: Fall 2006. http://www.ivc.illinois.edu/pubs lenrollPDF/SharpenFall06.pdf.

22. Wisconsin Technical College System. Online Courses Make Education Possible for Many Students. http://www.wtcsystem.edu/news/releases/online_courses.htm.

\section{ABOUT THE AUTHORS}

David K. Larson is an Assistant Professor of Management Information Systems in the College of Business and Management, Department of Management Information Systems, at the University of Illinois at Springfield. He earned his B.S. in Economics and M.A in Business Administration from the University of Illinois at Springfield and an Ed.D from Illinois State University. He is certified as a Master Online Teacher. He also is a Certified Computing Professional and Project Management Professional. He has been teaching using the online mode for over six years and using the blended mode for nearly three years.

Chung-Hsien Sung is an Associate Professor of Mathematical Sciences in the College of Liberal Arts and Sciences, Department of Mathematical Sciences, at the University of Illinois at Springfield. He earned his B.S. in Mathematical Statistics from Tamkang College and M.A in Mathematics from the Truman State University and Ph.D. in Statistics from Oklahoma State University. He has been teaching statistics for twenty five years and using the online mode for over ten years. 